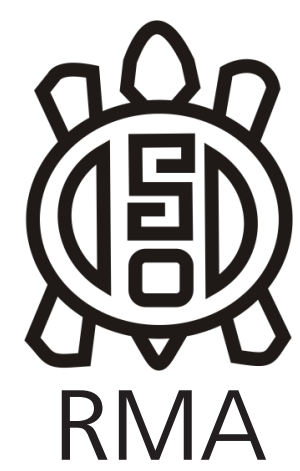

Dossier

\title{
Tras la interpretación: otros materialismos y ontologías en arqueologías argentinas actuales
}

\author{
Beyond interpretation: other materialisms and ontologies in current \\ argentine archaeologies
}

Andrés Laguens*

*Instituto de Antropología de Córdoba (IDACOR), CONICET- Universidad Nacional de Córdoba, Facultad de Filosofía y Humanidades, Argentina.

E-mail: laguens@ffyh.unc.edu.ar

El presente dossier presenta casos de estudio y reflexiones a partir de las experiencias de investigadoras e investigadores jóvenes de Argentina en diálogo con líneas de pensamiento contemporáneas en arqueología, en antropología, en los estudios de cultura material y en la filosofía, las que comparten un interés común en torno a ir un poco más allá de las formas habituales de interpretación.

La idea central es que la interpretación no surge simplemente de concebir a los artefactos materiales como signos de otra cosa, de un pasado que fue, sino de múltiples interconexiones, dinámicas, tanto materiales como inmateriales, que van desde cómo entender la materialidad del mismo registro arqueológico hasta los contextos locales de producción de conocimiento, pasando por formas propias y nativas de entender lo material y el mundo; planteos que ponen a prueba modos novedosos de pensar lo arqueológico, o la arqueología misma.

¿Por qué tras la interpretación? La propuesta del dossier está inspirada en la invitación de Jones y Alberti (2013) en Archaeology after interpretation, que significa no sólo hacer una arqueología en el presente después de la arqueología interpretativa, sino también otras formas de hacerla. After en inglés es después, pero también tras, una arqueología tras la interpretación, pero la que aun así también puede ir en pos de otra interpretación. En la idea original de esos autores, esa invitación apunta a hacer una arqueología que se diferencie de la arqueología interpretativa inglesa planteada desde inicios de la década de 1990 (Shanks y Hodder 1995). Pero tras la interpretación no sugiere otro momento disciplinario para aquellos autores, ni una nueva teoría, pero sí refleja cambios en el carácter epistemológico y ontológico del pensamiento arqueológico a partir de este siglo (Jones y Alberti 2013: 15). Éstos tienen que ver con "el efecto de difracción de regresar a fuentes similares pero con nuevas visiones, nuevas preguntas y, por lo tanto, nuevas posibilidades" (op. cit: 31), en el cual los materiales, las fuerzas de las cosas y las personas - tanto las del pasado como quienes hacen arqueología en el presente - son puestas todas en relación en el devenir del proceso arqueológico, en donde se ensamblan y articulan produciendo diferentes efectos o afectaciones. De allí emergen arqueologías más allá de la interpretación, arqueologías que, a nuestro entender, intervienen de manera dinámica en el mundo y abren nuevas posibilidades, aún en pos de interpretaciones.

Pero ese tras la interpretación en el aquí y ahora local adquiere un matiz diferente al que proponen estos autores. La historia del pensamiento y la producción académica en Argentina de las últimas décadas no siguió necesariamente los mismos caminos desde donde ellos parten. Consideramos que desde cierto punto de vista no es tan neto en el panorama de la arqueología en Argentina el poder afirmar que haya habido o exista un movimiento interpretativo a la par del internacional, sino que tiene su giro particular. Sin dudas a partir de la última década del siglo pasado se han comenzado a plantear, y hoy se siguen planteando, una multiplicidad de líneas de indagación y reflexión que han abierto a otras formas de entender la arqueología misma, las relaciones con las cosas, con la gente del pasado y el presente, la temporalidad y hasta la propia práctica profesional, pero desde miradas mucho más situadas desde Sudamérica, que etiquetarlas como líneas interpretativas encubriría su riqueza intelectual diversa'. Lo que sí es claro de ellas es que se alejan de epistemologías positivistas e intentan acercarse a lo arqueológico desde otras formas de pensar, no solo desde otras epistemologías, sino también desde otras ontologías de lo arqueológico. En un sentido general, las podemos entender como líneas que están tras la interpretación en tanto la superan o, como sostenemos, se abren a intervenir de diferentes formas en los mundos de las cosas, las personas y las relaciones,

\footnotetext{
1 Podríamos mencionar varios artículos de diferentes autoras y autores de Argentina para ejemplificar estas líneas de indagación, pero la lista sería muy extensa y mucho más allá de unos ejemplos, lo cual nunca haría justicia al total de producciones que podrían citarse. Además, es claro que tampoco podríamos englobarlas a todas ellas en una sola orientación, ya que si bien se trata de trabajos afines en los planteos, están hechos desde varias perspectivas y desconocemos si los autoras y autores se autoidentificarían con algún grupo teórico en particular.
} 
pero de manera más situadas.

Los trabajos aquí presentados son elaboraciones de jóvenes que transitan la producción de sus tesis de doctorado en distintas universidades nacionales, quienes en su mayoría fueron invitados e invitadas a participar en el dossier con el fin de brindarles un espacio donde pudieran experimentar en torno de otras manera de indagar acerca de formas de poner las cosa en relación. Esto resultó en un desafío no solo teórico y reflexivo, sino también uno metodológico en cuanto a que implicó pensar el registro arqueológico en una clave diferente a la acostumbrada, lo cual no es una tarea fácil. Como un efecto de ello resultaron contribuciones en las que incluso revisan las propias concepciones previas en sus investigaciones, con miradas que se mueven entre los nuevos materialismos y otras formas de concebir la materialidad, que discurren entre ontologías nativas sudamericanas y perspectivas no representacionales, junto a otras formas de pensar los contextos arqueológicos, a los mundos de otros, a las cosas y hasta lo local. Son diversas miradas que en los diferentes trabajos se enlazan entre sí desde posiciones que, en definitiva, tratan de romper con las dicotomías tradicionales de las personas y las cosas.

Se trata de ensayos, algunos de carácter quizás más exploratorios que otros, que toman como casos distintos tiempos y espacios geográficos (el Noroeste argentino, la
Patagonia o el litoral fluvial del río Paraná y del Uruguay). Benjamin Alberti tuvo la amabilidad de contribuir con su perspectiva con un trabajo de cierre sobre el dossier.

Creemos que los artículos, desde las propias experiencias y prácticas de jóvenes investigadoras e investigadores, junto con los aportes de revisoras y revisores de los artículos, logran explorar, reflexionar y poner a prueba otras formas de relacionarse con el registro arqueológico. En definitiva, de intentar a aproximarse a pensar otras arqueologías posibles tras la interpretación desde arqueologías argentinas actuales.

Córdoba, junio de 2021

\section{Bibliografía}

Jones, A. M. y Alberti, B. (2013) Archaeology after interpretation. En Alberti, B., A. M. Jones y J. Pollard (eds.) Archaeology after interpretation. Returning materials to archaeological theory (Cap.1, pp. 15-42), Walnut Creek, California.

Shanks, M. y Hodder, I. (1995) Processual, postprocessual and interpretative archaeologies. En: Hodder, I., Shanks, M., Alexandri, A., Buchli, V., Carman, J., Last, J. y Lucas, G. (eds) Interpreting Archaeology: finding meaning in the Past (Cap. 1, pp. 3-29). London: Routledge. 